\title{
THE RELEASE OF CHLORIDE IONS FROM CONVENTIONAL GLASS-IONOMER CEMENTS
}

\author{
${ }^{\#}$ ALEKSANDAR DIMKOV*, ELIZABETA GJORGIEVSKA*, JOHN W. NICHOLSON** \\ *Department of Paediatric and Preventive Dentistry, Faculty of Dental Medicine, University "Ss Cyril and Methodius", \\ Skopje, Macedonia \\ **Bluefield Centre for Biomaterials, 67-68 Hatton Garden, London EC1N 8JY, UK and Dental Materials Science Unit, \\ Barts and The London School of Medicine and Dentistry, Queen Mary University of London, London E1 4NS, UK \\ \#E-mail: dimkovaleksandar@gmail.com
}

Submitted March 15, 2019; accepted May 26, 2019

\begin{abstract}
Keywords: Chloride ions, GIC, Antimicrobials, Cetylpyridinium chloride, Benzalkonium chloride
The objective of this study was to determining the level of released chloride ions from conventional glass-ionomer cements incorporated with two different types of antimicrobial agents - cetylpyridinium chloride and benzalkonium chloride, as well as to see the influence of incorporated antimicrobial agents on the process of chloride ions releasing. Two conventional glass-ionomer cements ChemFlex and Fuji IX were incorporated with a different percentage of the antimicrobial agents. The specimens were prepared according to the British Standards Institution Specifications for Dental Glass Ionomer Cements. 84 samples in total $(4 \times 6 \mathrm{~mm})$ were prepared - by six specimens of the conventional glass-ionomer cements Fuji IX and ChemFlex with various concentrations of antimicrobial agents added $-1 \%, 2 \%$ and $3 \%$, i.e. six samples for each antimicrobial agent and each concentration level, as well as, by other six samples of the same cements without any antimicrobial agents, to be used as a control group. The measurements were performed at 14 successive time intervals started in zero time and finished after seven days. The results obtained speak of a continual release of chloride ions from both analysed glass-ionomer cements with the addition of antimicrobial compounds, as well as with no antimicrobial compound incorporated.
\end{abstract}

\section{INTRODUCTION}

According to contemporary dental science, dental decay is a localised destruction of dental tissues caused by micro-organisms, mostly by mutans streptococci, resulting in dental structure destruction. Because of the relatively frequent occurrence of recurrent caries after a restorative treatment, and because of the huge number of cariogenic micro-organisms present in the oral cavity, which present a potential risk-factor regarding the development of new carious lesions, attention has increasingly been directed toward therapeutic antimicrobial effects of restorative materials.

The glass-ionomer cements distinguish themselves as most acceptable restorative materials possessing the positive characteristics of fluorine in the processes of re-mineralisation and antimicrobial action. According by Mazzaoui [1] two main reasons that have made GICs very popular are their permanent ionic bond to tooth structure, and their capacity to release fluoride, making them useful materials to replace dentin when used as bases in deep cavities. They are used most often for restorations of non-retentive and cervical cavities, and of cavities in milk teeth. The use in these cases is determined by their characteristic to release fluorine [2-6] and to participate in the mechanism of inhibition of development of secondary caries. [7-10]. At the same time they also act on the surrounding bacteria by reducing the cariogenic microorganisms [11-14]. The fact that glass-ionomer cements, as well as the resin modified glass-ionomer cements, possess the capacity for slow and sustainable release of fluoride ions during a long period, was confirmed in a vast number of studies [15-22].

In addition to the release of fluoride ions, GICs can potentially be used as templates for the release of other active antimicrobial components.

The most used antimicrobial agent to be incorporated in glass-ionomer cements in different concentrations and different percental ratios is Chlorhexidine. With reference to both its positive effects as an independent remedy, and its use as an additive in mouth rinses, there is a considerable number of studies that confirm the positive effect of the incorporation of Chlorhexidine in glass-ionomer cements, first of all its effect in the reduction of cariogenic salivary flora along with lesser or stronger impacts on the biochemical and physical properties of such cements [23-28].

Unfortunately, there is a very low number of data in the literature referring to the incorporation of other antimicrobial components in GICs. Although a part of them have a confirmed effect in the reduction of cariogenic 
salivary flora when used in rinses or toothpastes [29-37], the results regarding their incorporation in glass-ionomer cements are still scarce. Most often, they were added to the cements together with chlorhexidine to make a comparison of their effects in relation to chlorhexidine [38].

One of the most used antimicrobial agents are quaternary ammonium compounds, antiseptics belonging to the cationic antimicrobial agents.

The goal of this study was to determining the level of released chloride $\left(\mathrm{Cl}^{-}\right)$ions from conventional glass-ionomer cements incorporated with two different types of antimicrobial agents - cetylpyridinium chloride (CPC) and benzalkonium chloride (BZK), in a medium consisting of deionised water over different time periods, as well as to see the influence of incorporated antimicrobial agents on the process of chloride ions releasing. The motivation to carry out these analyses was the fact that the main ingredient of the antimicrobial compounds is chlorine, which has a confirmed antimicrobial effect, and that its possible release would indicate an antimicrobial effect of the GICs.

\section{EXPERIMENTAL}

\section{Methodology}

Studies were carried out using the commercial restorative grade glass-ionomer cements ChemFlex (ex Dentsply, Germany) and Fuji IX (ex GC, Japan). Antimicrobial compounds used were cetyl pyridinium chloride (CPC) - Sigma-Aldrich, Dorset, UK and benzalkonium chloride (BZK) - ex Fluka, Germany.

\section{Preparation of the samples and incorporation of antimicrobial components}

The specimens were prepared according to British Standards Institution Specifications for Dental Glass Ionomer Cements 1989. Samples with no antimicrobial agent incorporated (control group), were prepared by mixing a certain amount of powder and liquid on mixing glass plates by means of a metal spatula (according to the manufacturers' instructions). The freshly mixed paste was then put into $6 \mathrm{~mm}$ high metal moulds having $4 \mathrm{~mm}$ in diameter. (Figure 1) The moulds were closed by metal plates on both sides and were then placed in special G-clamps. Then the specimens were placed in an incubator at $37^{\circ} \mathrm{C}$ for one hour (maturation time). Once removed from the incubator, the specimens were taken out from the clamps and moulds, and stored individually in separate marked plastic tubes with $5 \mathrm{ml}$ of deionized water.

The antimicrobial compounds BZK and CPC were first incorporated into the glass ionomer cement's polyacrylic acid by mixing, and then the powder has been added gradually, quantity by quantity, to the previously prepared acid and antimicrobial compound mixture, while care has been taken to mix them together until complete saturation. The antimicrobial agent has been added in strict portions of 1,2 and $3 \%$ of the weight of the cement. The determination of the concentration (weight) of BZK and CPC was done by measuring the given percentage of the antimicrobial agent with an analytical scale (Mettler AE 200). Preceding analyses had determined the concentrations of 1,2 and $3 \%$ of antimicrobial agents to be equivalent to $0.0022 \mathrm{~g}, 0.0044 \mathrm{~g}$ and $0.0066 \mathrm{~g}$ of GIC ChemFlex, respectively, as well as $0.0032 \mathrm{~g} 0.0064 \mathrm{~g}$ and $0.0128 \mathrm{~g}$ of GIC Fuji IX. Then the specimens were placed in an incubator at $37{ }^{\circ} \mathrm{C}$ for one hour (maturation time). After removal from the incubator, the specimens were taken out from the clamps and moulds, and stored individually in separate marked plastic tubes with $5 \mathrm{ml}$ of deionized water at a temperature of $22-24{ }^{\circ} \mathrm{C}$ and at an air humidity of $40-50 \%$.

84 samples in total were prepared - by six specimens of the conventional glass-ionomer cements Fuji IX and ChemFlex with various concentrations of antimicrobial agents (CPC or BZK) added $-1 \%, 2 \%$ and $3 \%$, i.e. six samples for each antimicrobial agent and each concentration level, as well as, by other six samples of the same cements without any antimicrobial agents, to be used as a control group.

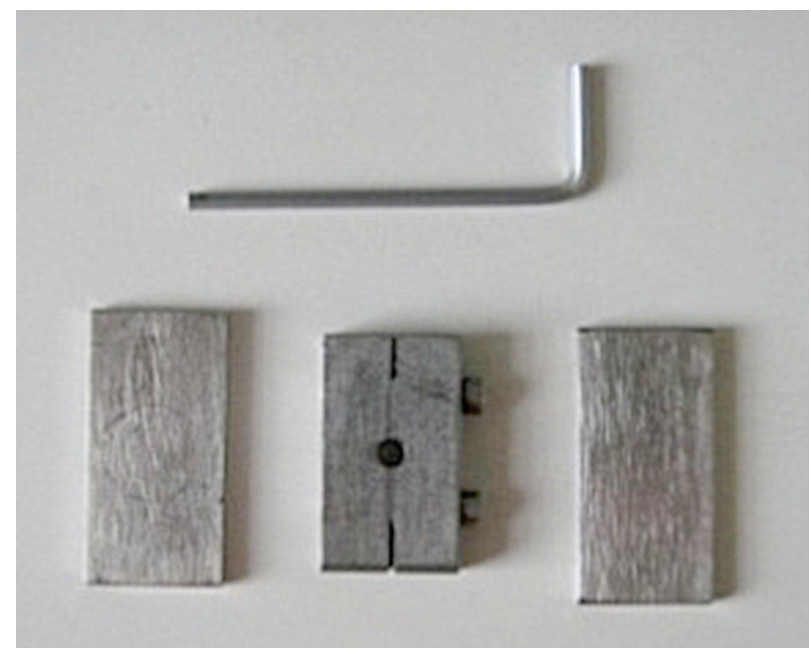

a)

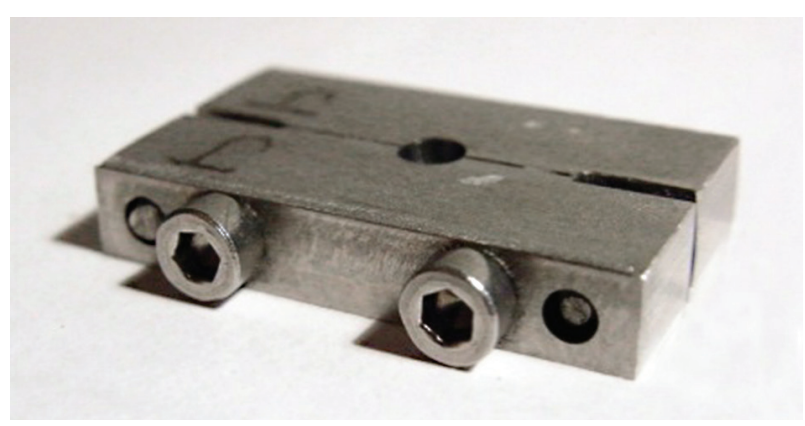

b)

Figure 1. Metal moulds for specimen preparation. 
The levels of released chloride ions were determined at different time intervals, as follows: immediately, after $15^{\prime}, 30^{\prime}, 45^{\prime}, 1,2,3,4,24$ and 48 hours, and after 4, 5, 6 and 7 days.

\section{Determination of the levels of released ions using ion-selective electrode}

The amounts of released $\mathrm{Cl}^{-}$ions were determined with the use of ion-selective electrode specified for chloride ions detection, using ORION 4 star pH.ISE Benchtop Thermo Electron Corporation USA. The electrode were previously calibrated by standards whose molarity was within the range of the concentrations of ions that were to be measured $(0.1,1.0,10.0,100.0$ and $1000.0 \mathrm{ppm})$. The release of chloride ions was done in a water medium of deionised water. Then, the ion-selective electrode was subsequently sunk in marked plastic laboratory tubes. Prior to each subsequent measurement, the plastic tubes were shaken for a few seconds to obtain a uniform distribution of released ions.

The results thus obtained were expressed in ppm and entered into working tables for each of the time intervals measured, and were than statistically analysed using 1-Way ANOVA and Post-hoc-Tukey honest significant difference (HSD) test.

\section{RESULTS}

The results obtained on the release of chloride ions from the ChemFlex cement incorporated with the three investigated concentrations of antimicrobial compounds speak of a continual release of these ions in the course of one week. According to the ANOVA test, the differences in the average values in the release of chloride ions from the ChemFlex glass-ionomer cement with the addition of $1 \%, 2 \%$ and $3 \%$ of the antimicrobial compound BZK are statistically significant over almost all time periods,

Table 1. Release of $\mathrm{Cl}^{-}$ions - ChemFlex + Benzalkonium Chloride (data obtained in ppm).

\begin{tabular}{lccccc}
\hline Time & $\begin{array}{c}0 \% \text { average } \pm \\
(\text { St. dev. })\end{array}$ & $\begin{array}{c}1 \% \text { average } \pm \\
(\text { St. dev. })\end{array}$ & $\begin{array}{c}2 \% \text { average } \pm \\
(\text { St. dev. })\end{array}$ & $\begin{array}{c}3 \% \text { average } \pm \\
(\text { St. dev. })\end{array}$ & $\begin{array}{c}\text { ANOVA } \\
(\mathrm{p}<0.05)\end{array}$ \\
\hline $0^{\prime}$ & $0.07(0.04)$ & $0.24(0.04)$ & $0.40(0.19)$ & $0.41(0.01)$ & $0.034504^{*}$ \\
15, & $0.14(0.19)$ & $0.46(0.06)$ & $2.21(0.28)$ & $2.30(0.62)$ & $0.000001^{*}$ \\
$30^{\prime}$ & $0.22(0.21)$ & $0.81(0.08)$ & $3.86(0.98)$ & $9.12(1.78)$ & $0.000000^{*}$ \\
$45^{\prime}$ & $0.31(0.27)$ & $6.36(0.87)$ & $5.55(1.45)$ & $10.24(1.25)$ & $0.000014^{*}$ \\
1 hour & $0.75(0.68)$ & $8.21(0.76)$ & $7.06(1.77)$ & $10.96(1.77)$ & $0.001410^{*}$ \\
2 hours & $3.72(4.91)$ & $15.99(1.05)$ & $10.92(2.09)$ & $12.80(1.47)$ & $0.000224^{*}$ \\
3 hours & $15.18(7.37)$ & $35.85(4.97)$ & $18.31(4.48)$ & $15.35(1.19)$ & $0.000000^{*}$ \\
4 hours & $20.40(8.23)$ & $51.03(3.76)$ & $23.69(2.88)$ & $18.56(2.11)$ & $0.000000^{*}$ \\
24 hours & $8.43(7.07)$ & $19.63(2.19)$ & $16.51(2.02)$ & $21.08(3.40)$ & $0.024349^{*}$ \\
3 days & $12.57(4.39)$ & $25.33(1.76)$ & $24.16(2.13)$ & $34.06(2.61)$ & $0.000002^{*}$ \\
4 days & $21.83(3.80)$ & $60.94(2.86)$ & $60.19(1.49)$ & $64.32(2.19)$ & $0.014225^{*}$ \\
5 days & $12.63(3.04)$ & $32.56(2.23)$ & $33.33(1.21)$ & $41.75(1.67)$ & $0.000000^{*}$ \\
6 days & $19.37(2.99)$ & $52.38(2.91)$ & $54.37(6.76)$ & $49.63(3.32)$ & 0.241242 \\
7 days & $28.47(1.66)$ & $112.72(8.68)$ & $122.00(2.26)$ & $149.92(6.87)$ & $0.000000^{*}$ \\
\hline
\end{tabular}

Table 2. Release of $\mathrm{Cl}^{-}$ions - ChemFlex $+\mathrm{CPC}$ (data obtained in ppm).

\begin{tabular}{|c|c|c|c|c|c|}
\hline Time & $\begin{array}{c}0 \% \text { average } \pm \\
\text { (St. dev.) }\end{array}$ & $\begin{array}{c}1 \% \text { average } \pm \\
\text { (St. dev.) }\end{array}$ & $\begin{array}{c}2 \% \text { average } \pm \\
\text { (St. dev.) }\end{array}$ & $\begin{array}{c}3 \% \text { average } \pm \\
\text { (St. dev.) }\end{array}$ & $\begin{array}{c}\text { ANOVA } \\
(\mathrm{p}<0.05)\end{array}$ \\
\hline 0 ' & $0.07(0.04)$ & $0.05(0.02)$ & $0.06(0.02)$ & $0.39(0.27)$ & $0.002904 *$ \\
\hline $15^{\prime}$ & $0.14(0.19)$ & $0.39(0.13)$ & $2.35(4.15)$ & $19.20(1.36)$ & $0.000000 *$ \\
\hline $30^{\prime}$ & $0.22(0.21)$ & $0.54(0.09)$ & $9.39(4.05)$ & $26.68(2.06)$ & $0.000000^{*}$ \\
\hline $45^{\prime}$ & $0.31(0.27)$ & $2.43(1.05)$ & $16.02(4.42)$ & $38.73(3.68)$ & $0.000000^{*}$ \\
\hline 1 hour & $0.75(0.68)$ & $9.43(4.51)$ & $20.02(3.84)$ & $45.97(4.32)$ & $0.000000^{*}$ \\
\hline 2 hours & $3.72(4.91)$ & $16.18(4.98)$ & $34.47(4.88)$ & $95.27(12.45)$ & $0.000000 *$ \\
\hline 3 hours & $15.18(7.37)$ & $43.58(10.33)$ & $53.07(7.65)$ & $81.87(11.44)$ & $0.000020 *$ \\
\hline 4 hours & $20.40(8.23)$ & $56.10(12.13)$ & $42.78(6.20)$ & $65.30(13.02)$ & $0.009289^{*}$ \\
\hline 24 hours & $8.43(7.07)$ & $20.17(3.54)$ & $25.48(3.71)$ & $60.67(13.69)$ & $0.000001 *$ \\
\hline 3 days & $12.57(4.39)$ & $23.02(2.32)$ & $32.63(4.29)$ & $73.40(19.65)$ & $0.000004 *$ \\
\hline 4 days & $21.83(3.80)$ & $57.88(3.66)$ & $75.15(10.12)$ & $219.83(44.36)$ & $0.000000 *$ \\
\hline 5 days & $12.63(3.04)$ & $28.10(2.02)$ & $34.60(5.12)$ & $121.83(29.05)$ & $0.000000 *$ \\
\hline 6 days & 19.37 (2.99) & $53.02(2.81)$ & $54.38(8.41)$ & $111.70(25.42)$ & $0.000009 *$ \\
\hline 7 days & $28.47(1.66)$ & $107.50(6.53)$ & $130.17(23.08)$ & $253.50(43.43)$ & $0.000000 *$ \\
\hline
\end{tabular}


for $\mathrm{p}<0.05$. The difference in the average values of ChemFlex - BZK is not statistically significant only for the sixth day (Table 1).

The statistical analysis conducted for the other antimicrobial compound - CPC, added in GIC ChemFlex, exhibited statistically significant differences over all time periods, for $p<0.05$ (Table 2). According to the Tukey HSD test, the differences in the average values are statistically significant for $\mathrm{p}<0.00$ between the average values of ChemFlex $-3 \% \mathrm{CPC}$ and the average values of ChemFlex $-1 \%$ and $2 \%$ CPC.

The variance analysis conducted for the Fuji IX GIC incorporated with the three concentrations of the antimicrobials are shown statistically significant differences in all time periods, for $\mathrm{p}<0.05$ with the exemption for the $15^{\text {th }}$ minute in the CPC combination (Tables 3 and 4).

According to the Tukey HSD test, the differences in the average values are statistically significant for $\mathrm{p}<0.00$ between the average values of Fuji IX $+2 \%$ CPC and of Fuji IX $+1 \%$ and $3 \% \mathrm{CPC}$; between the average values of Fuji IX $+1 \%$ BZK and of Fuji IX $+2 \%$ and $3 \%$ BZK.

The results from the comparative analysis of the data on the average values of released chloride ions in the course of time, for each concentration of antimicrobial compound individually, are shown that in the case of $1 \%$ the highest average release is given by the combinations of ChemFlex with both antimicrobial agents, in the case of $2 \%$ of the antimicrobial compounds the highest average release is given by the combination Fuji IX with both antimicrobial agents and in the case of $3 \%$ of the antimicrobial compound the highest release exists for the combination of ChemFlex with CPC (Chart 1, 2 and 3).

The results of the average values of released chloride ions with no antimicrobial agent added, over the time periods are shown moderate and constantly releasing of the chloride ions with increasing trend, especially after 1 hour (Chart 4).

Table 3. Release of $\mathrm{Cl}^{-}$ions - Fuji IX $+\mathrm{CPC}$ (data obtained in ppm).

\begin{tabular}{lccccc}
\hline Time & $\begin{array}{c}0 \% \text { average } \pm \\
\text { (St. dev. })\end{array}$ & $\begin{array}{c}1 \% \text { average } \pm \\
(\text { St. dev. })\end{array}$ & $\begin{array}{c}2 \% \text { average } \\
(\text { St. dev. })\end{array}$ & $\begin{array}{c}3 \% \text { average } \pm \\
(\text { St. dev. })\end{array}$ & $\begin{array}{c}\text { ANOVA } \\
(\mathrm{p}<0.05)\end{array}$ \\
\hline $0^{\prime}$ & $0.17(0.02)$ & $0.02(0.01)$ & $0.13(0.02)$ & $0.02(0.01)$ & $0.000000^{*}$ \\
15 & $0.53(0.10)$ & $0.34(0.16)$ & $1.03(0.72)$ & $1.19(1.11)$ & 0.161596 \\
$30^{\prime}$ & $0.69(0.14)$ & $0.77(0.29)$ & $1.84(2.03)$ & $10.36(2.75)$ & $0.000001^{*}$ \\
$45^{\prime}$ & $0.44(0.13)$ & $1.93(1.20)$ & $4.83(3.39)$ & $15.10(2.09)$ & $0.000000^{*}$ \\
1 hour & $1.77(0.99)$ & $6.45(2.29)$ & $3.63(3.25)$ & $25.37(2.01)$ & $0.000000^{*}$ \\
2 hours & $13.23(1.60)$ & $13.10(1.64)$ & $23.83(3.02)$ & $90.77(7.05)$ & $0.000000^{*}$ \\
3 hours & $12.39(3.23)$ & $29.08(2.55)$ & $26.23(3.44)$ & $148.33(10.46)$ & $0.000000^{*}$ \\
4 hours & $11.66(4.97)$ & $36.00(4.02)$ & $43.05(5.90)$ & $134.00(10.92)$ & $0.000000^{*}$ \\
24 hours & $3.11(2.30)$ & $11.15(1.18)$ & $22.83(3.56)$ & $21.90(2.19)$ & $0.000001^{*}$ \\
3 days & $9.28(5.88)$ & $73.85(7.09)$ & $140.50(18.43)$ & $56.32(5.97)$ & $0.000000^{*}$ \\
4 days & $50.85(7.92)$ & $30.43(3.14)$ & $61.70(10.78)$ & $34.05(2.92)$ & $0.000001^{*}$ \\
5 days & $23.17(3.33)$ & $39.38(5.69)$ & $76.38(14.17)$ & $87.47(9.52)$ & $0.000002^{*}$ \\
6 days & $32.00(3.65)$ & $75.25(16.08)$ & $110.72(22.43)$ & $50.70(4.58)$ & $0.000045^{*}$ \\
7 days & $63.43(10.27)$ & $21.53(4.68)$ & $43.15(14.59)$ & $56.68(6.75)$ & $0.000056^{*}$ \\
\hline
\end{tabular}

Table 4. Release of $\mathrm{Cl}^{-}$ions - Fuji IX + Benzalkonium Chloride (data obtained in ppm).

\begin{tabular}{lccccc}
\hline Time & $\begin{array}{c}0 \% \text { average } \pm \\
(\text { St. dev. })\end{array}$ & $\begin{array}{c}1 \% \text { average } \pm \\
(\text { St. dev. })\end{array}$ & $\begin{array}{c}2 \% \text { average } \pm \\
(\text { St. dev. })\end{array}$ & $\begin{array}{c}3 \% \text { average } \pm \\
(\text { St. dev. })\end{array}$ & $\begin{array}{c}\text { ANOVA } \\
(\mathrm{p}<0.05)\end{array}$ \\
\hline $0^{\prime}$ & $0.17(0.02)$ & $0.06(0.01)$ & $14.13(2.14)$ & $11.13(0.60)$ & $0.000000^{*}$ \\
15, & $0.53(0.10)$ & $0.47(0.18)$ & $30.28(4.13)$ & $30.57(2.68)$ & $0.000000^{*}$ \\
$30^{\prime}$ & $0.69(0.14)$ & $1.01(0.31)$ & $33.75(2.44)$ & $38.87(3.27)$ & $0.000000^{*}$ \\
$45^{\prime}$ & $0.44(0.13)$ & $11.31(1.62)$ & $34.62(2.15)$ & $48.87(0.97)$ & $0.000000^{*}$ \\
1 hour & $1.77(0.99)$ & $16.13(2.99)$ & $46.73(6.56)$ & $67.85(3.56)$ & $0.000000^{*}$ \\
2 hours & $13.23(1.60)$ & $22.27(3.79)$ & $82.10(9.91)$ & $43.25(2.25)$ & $0.000000^{*}$ \\
3 hours & $12.39(3.23)$ & $68.75(5.35)$ & $70.33(12.55)$ & $87.72(11.38)$ & $0.010247^{*}$ \\
4 hours & $11.66(4.97)$ & $59.67(4.72)$ & $115.82(22.62)$ & $126.50(13.85)$ & $0.000004^{*}$ \\
24 hours & $3.11(2.30)$ & $32.72(2.83)$ & $42.42(8.12)$ & $56.67(2.67)$ & $0.000004^{*}$ \\
3 days & $9.28(5.88)$ & $19.55(1.92)$ & $28.60(6.54)$ & $34.67(1.42)$ & $0.000040^{*}$ \\
4 days & $50.85(7.92)$ & $24.90(6.02)$ & $44.75(15.38)$ & $77.43(10.17)$ & $0.000003^{*}$ \\
5 days & $23.17(3.33)$ & $57.17(10.62)$ & $97.87(29.96)$ & $155.50(28.05)$ & $0.000019^{*}$ \\
6 days & $32.00(3.65)$ & $42.90(9.79)$ & $73.82(21.08)$ & $101.07(26.62)$ & $0.000712^{*}$ \\
7 days & $63.43(10.27)$ & $64.40(19.29)$ & $90.62(30.40)$ & $167.83(40.71)$ & $0.000115^{*}$ \\
\hline
\end{tabular}




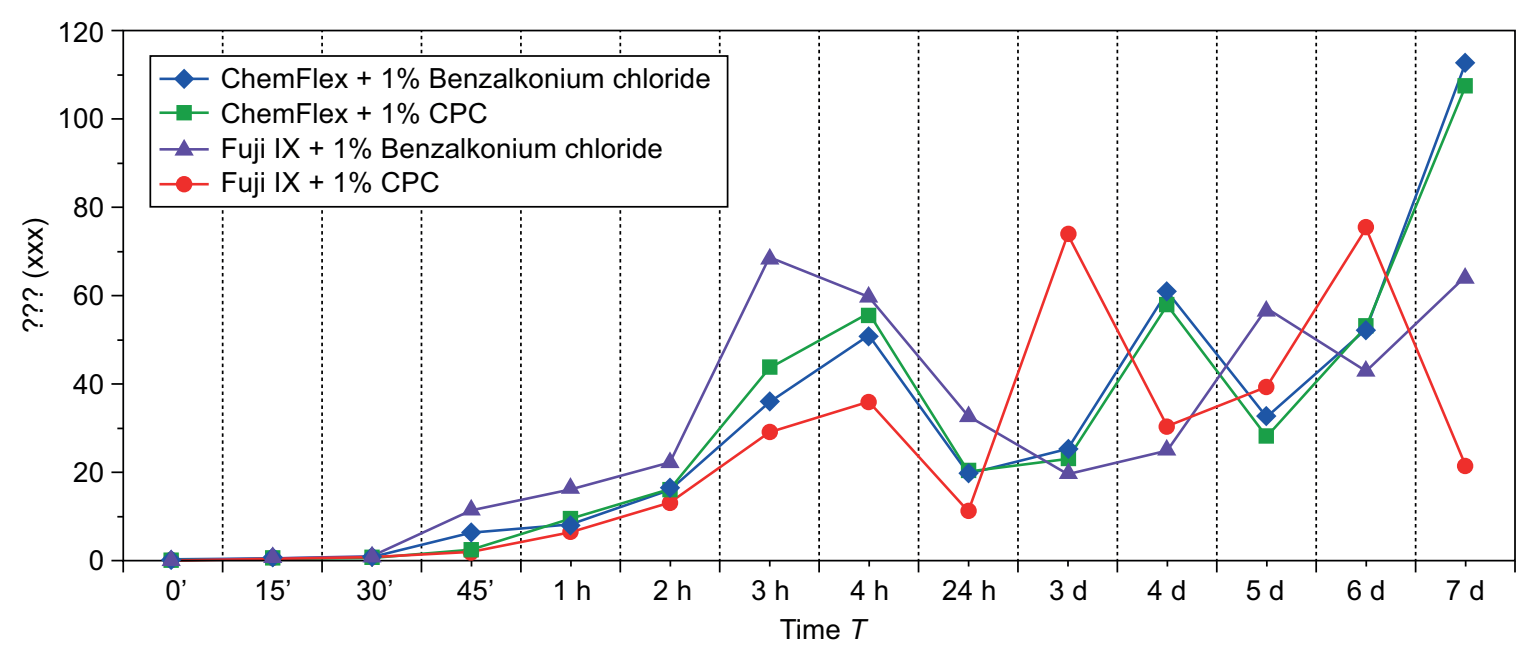

Chart 1. Comparison of $1 \%$ antimicrobial agents in conventional GIC-s.

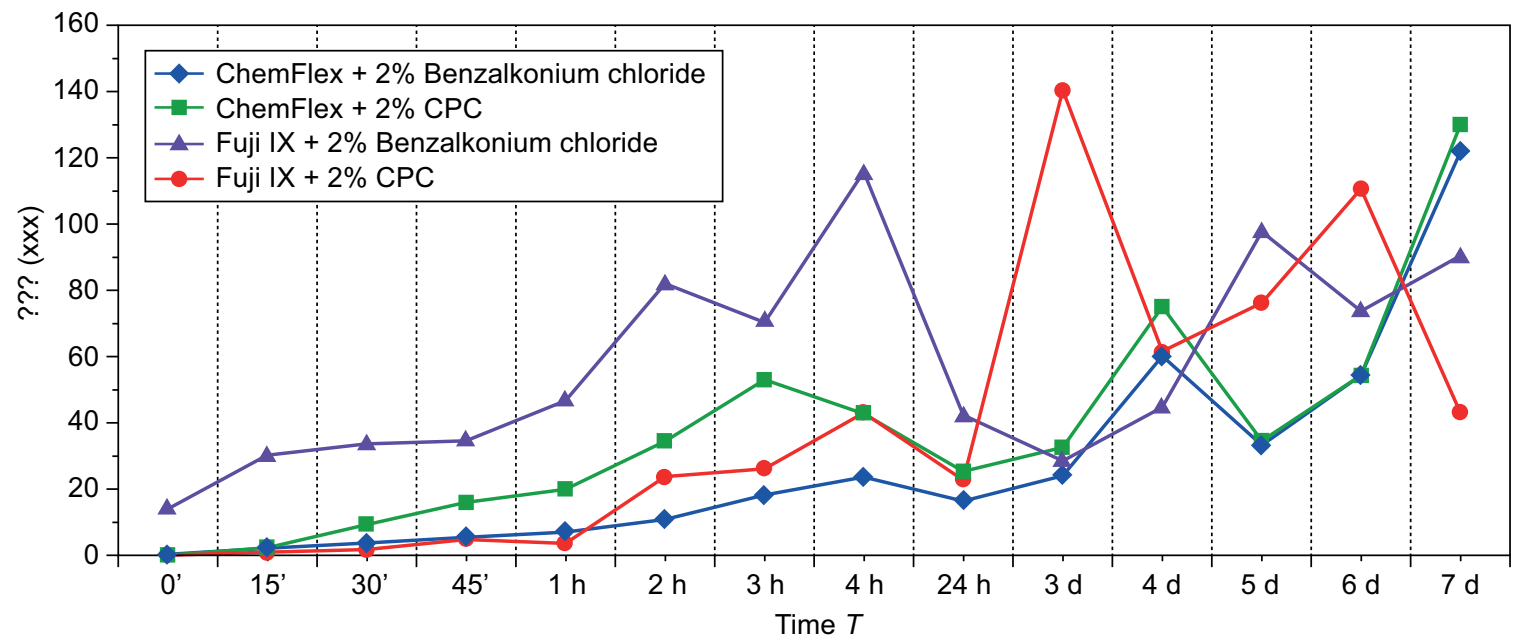

Chart 2. Comparison of $2 \%$ antimicrobial agents in conventional GIC-s.

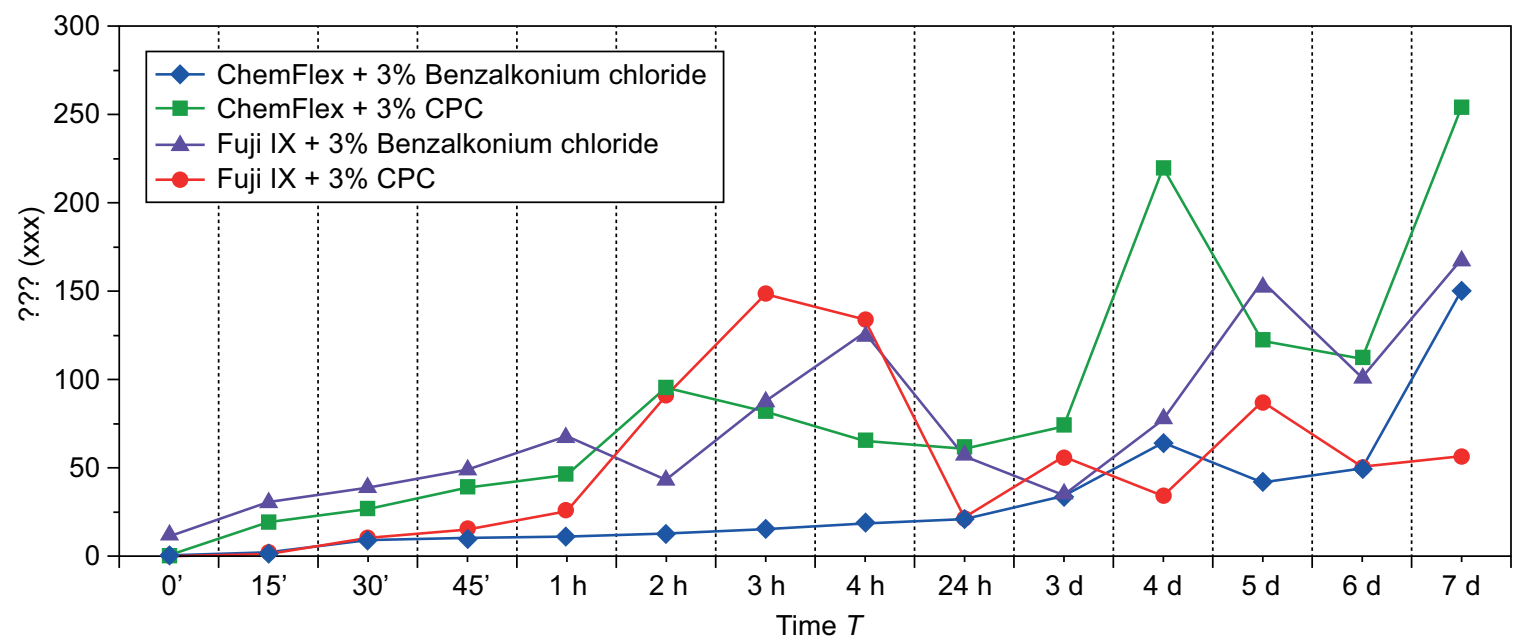

Chart 3. Comparison of $3 \%$ antimicrobial agents in conventional GIC-s. 


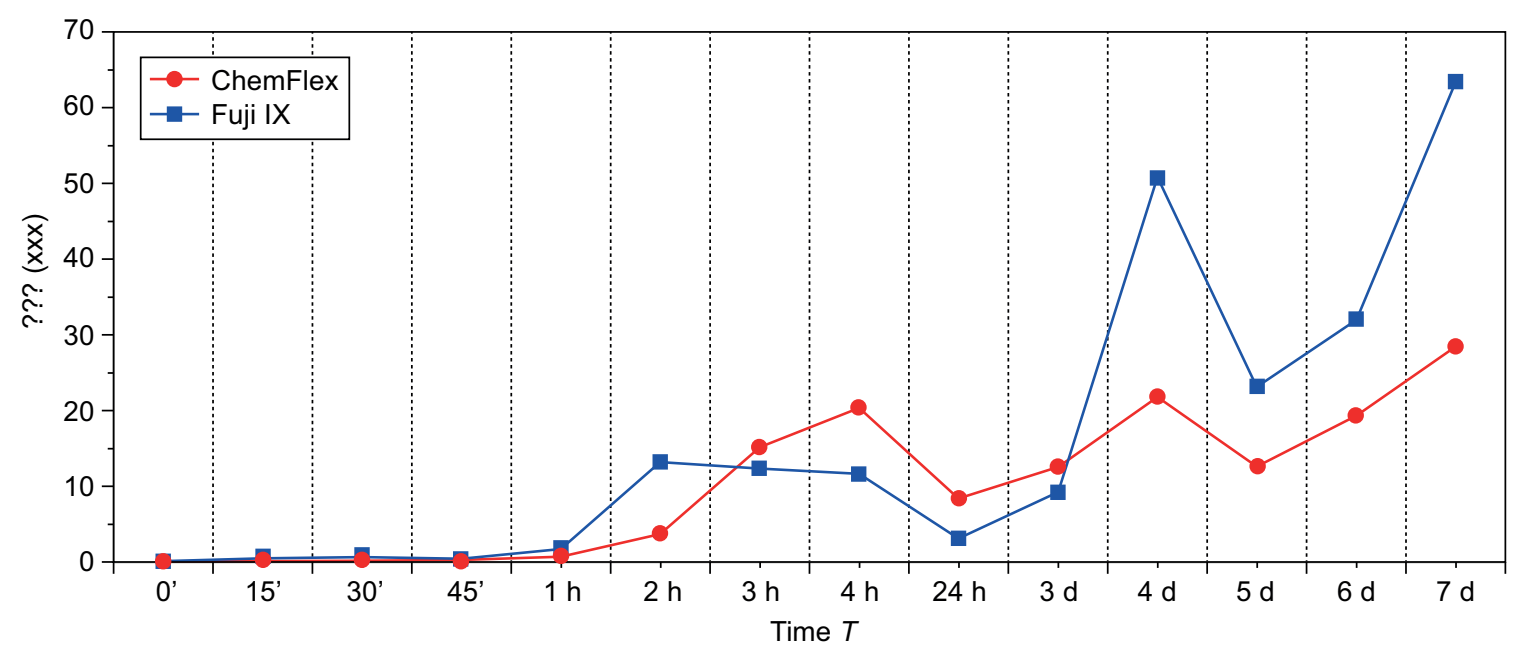

Chart 4. Average values of released $\mathrm{Cl}^{-}$ions with no antimicrobial agent added.

\section{DISCUSSION}

One of the most frequently used methods for detection of elements and compounds in liquid medium is the ion-selective electrode (ISE). It is used in the analysis of the release of fluoride and other ions in the deionised water medium, and especially in the analysis of glass-ionomer cements and other dental materials $[1,4,15,17-21]$.

The most often antimicrobial agent incorporated in glass-ionomer to increase the antimicrobial effects of the glass-ionomer cements is Chlorhexidine [23-28].

Unfortunately, there is a very low number of data in the literature referring to the incorporation of other antimicrobial components in GICs. Although a part of them have a confirmed effect in the reduction of cariogenic salivary flora when used in rinses or toothpastes [29-37], the results regarding their incorporation in glass-ionomer cements are still scarce. Most often, they were added to the cements together with chlorhexidine to make a comparison of their effects in relation to chlorhexidine [38].

The results obtained on the release of chloride ions from the ChemFlex cement incorporated with the three investigated concentrations of antimicrobial compounds speak of a continual release of these ions in the course of one week.

The individual values of chloride ions for each percentage at a given time period are different, the release exhibiting a fluctuating curve, with increases and decreases in the values, and at the end of the observed period the combination ChemFlex - CPC releases a larger amount of chloride ions, for $2 \%$ and $3 \%$ of the antimicrobial component. In the case of the one percent of the antimicrobial component, the same GIC, but with the BZK compound releases a larger amount of chloride ions.

As regards the analysis of the results for the other glass-ionomer cement - Fuji IX, the release of chloride ions in all three investigated concentrations is higher for the combination of the cement with the BZK compound than for the combination with CPC.

From the graphical illustrations one can perceive the parallelism of the curves of the average values of released chloride ions from GIC ChemFlex for the two analysed compounds, and disparate in the case of the Fuji IX cement. We obtain similar data also for $2 \%$ of antimicrobial compounds. The release of chloride ions for the antimicrobial compound incorporated with $3 \%$ points to the existence of a complete fluctuation of the values in the course of the investigated period. What can also be seen is the overall higher release of chloride ions from the Fuji IX GIC with respect to ChemFlex. Nevertheless, the release for Fuji IX is accompanied with many rather expressed peaks of the curves, in particular after the second hour. The highest individual release of chloride ions among all combinations, is given by the combination ChemFlex - $3 \%$ CPC.

What is interesting is the data about the continual release of chloride ions from the GICs with no anti-microbial compounds incorporated.

Unfortunately, no data could be found, either in the references, or in Medline database, on the existence or the release of chloride ions in/from glass-ionomer cements. Furthermore, neither do manufacturers in the specifications of the analysed cements refer to any existence of chloride ions in their compositions. Therefore the question arises as to where are the chloride ions in the analysed medium released from, in concentrations at that which in certain periods are even higher than the concentrations in the media in which samples of cements with incorporated antimicrobial compounds (Fuji IX CPC and to a certain degree Fuji IX - BZK) were stored. Though the cumulative release effect is analysed, the level of the released chloride ions rise continually, giving evidence about their permanent release. It is certain that these concentrations do not come from the medium itself (deionised water), considering the fact that the use of the 
specific ISE does not show any existence of chloride ions in a medium without cement samples. The possibility of an external (aero) introduction, i.e. a secondary pollution of the medium, is also rejected on two grounds - the concentrations of chlorine in the air within the laboratory are reduced to zero and the laboratory tubes in which the samples and the medium had been contained were closed after the completion of each measurement. Even if there were an exact estimate of the concentration of chlorine in the air, the incorporation of ions from the air into a water medium in a relatively short time would be questionable. The detection of chloride ions from glassionomer cements will be the subject of one of the future analyses.

\section{CONCLUSIONS}

The release of chloride ions from the analysed glass-ionomer cements with the incorporation of the antimicrobial compounds is directly proportional to the increase in the concentration of the compounds. The glass-ionomer cements, with no antimicrobial compound incorporated release chloride ions, but in smaller quantities.

When comparing the same concentrations of the antimicrobial compounds, a higher release of chloride ions from the GICs is obtained from the combinations: $1 \%$ of BZK, and $2 \%$ and $3 \%-\mathrm{CPC}$, incorporated in ChemFlex, and all three concentrations with BZK incorporated in Fuji IX.

On the average, more chloride ions are released from the Fuji IX glass-ionomer cement than from the ChemFlex cement, and the individual largest release of chloride ions among all combinations is given by the combination ChemFlex - $3 \%$ CPC.

\section{Acknowledgment}

The research presented in this paper is a part of a wider range research done in the scope of my PhD thesis performed at the School of Science, University of Greenwich, UK and at the Faculty of Dental Medicine - Skopje, R.Macedonia. I would like to thank Professor John W. Nicholson for the award of a Visiting Fellowship which allowed me to do experiments with the mechanical and chemical properties of glass-ionomer cements.

\section{REFERENCES}

1. Mazzaoui S.A., Burrow M.F., Tays M.J. (2000): Fluoride release from glass ionomer cements and resin composites coated with a dentin adhesive. Dental Materials, 16, 166-171. Doi: 10.1016/S0109-5641(00)00003-8

2. Attar N., Onen A. (2002): Fluoride release and uptake characteristics of aestetic restorative materials. Journal of
Oral Rehabilitation, 29, 791-798. doi:10.1046/j.1365-2842. 2002.00902.x

3. Billington R.W, Williams J.A., Dorban A., Pearson G.J. (2004): Glass ionomer cement: evidence pointing to fluorine release in the form of monofluorophosphate in addition to fluoride ion. Biomaterials, 25, 3399-3402. doi: 10.1016/j. biomaterials.2003.10.028

4. Dionysopoulos P., Kotsanos N., Pataridou A. (2003): Floride release and uptake by four new fluoride releasing restorative materials. Journal of Oral Rehabilitation, 30(9), 866-872. doi:10.1046/j.1365-2842.2003.00993.x

5. Williams J.A., Billington R.W., Pearson G.J. (1999): Comparison of ion release from glass ionomer cement as a function of the method of incorporation of added ions. Biomaterials, 20, 589-594. doi: 10.1016/S0142-9612(98) 00213-0

6. Williams J.A., Briggs E., Billington R.W., Pearson G.J. (2003): The effects of adding fluoride compounds to a fluoride-free glass-ionomer cement on a subsequent fluoride and sodium release. Biomaterials, 24, 1301-1308. doi:10.1016/ S0142-9612(02)00467-2

7. Berg J.H. (1998): The continuum of restorative materials in pediatric dentistry - a review for the clinician Pediatric Dentistry, 20(2), 93-100.

8. McLean J.W., Nicholson J.W.; Wilson A.D. (1994): Proposed nomenclature for glass-ionomer dental cements and related materials. Quintessence Int, 25(9), 587-589.

9. Nicholson J.W. (2000): Adhesive dental materials and their durability. International Journal of Adhesion and Adhesives, 20, 11-16. doi:10.1016/S0143-7496(99)00009-3

10. Nicholson J.W. (1998): Chemistry of glass-ionomer cements: a review. Biomaterials, 19, 485-494. doi: 10.1016/ S0142-9612(97)00128-2

11. Davidovich E., Weiss E., Fuks A.B., Beyth N. (2007): Surface antibacterial properties of glass ionomer cements used in atraumatic restorative treatment. The Journal of the American Dental Association, 138, 1347-1352. doi: 10.14219/jada.archive.2007.0051

12. Hengtrakool C., Pearson G.J., Wilson M. (2006): Interaction bettween GIC and S.sanguis biofilms: Antibacterial properties and changes of surface hardness. Journal of Dentistry, 34, 588-597. doi: 10.1016/j.jdent.2005.02.011

13. Roshan N.M., Shigli A.L., Desphande S.D. (2010): Microbiological evaluation of salivary Streptococcus mutans from children of age 5-7 years, pre- and post-traumatic restorative treatment. Contemporary Clinical Dentistry, 1(2), 94-97. doi: 10.4103/0976-237X.68602

14. Vermeersch G., Leloup G., Delmee M., Vreven J. (2005): Antibacterial activity of glass-ionomer cements, compomers and resin composites: relationship between acidity and material setting phase. Journal of Oral Rehabilitation, 32, 368-374. doi: 10.1111/j.1365-2842.2004.01300.x

15. DeSchepper E.J., Berry E.A., Cailleteau J.G., Tate W.H. (1991): A comparative study of fluoride release from glassionomer cements. Quintessence Int, 22, 215-220.

16. Diaz-Arnold A.M., Holmes D.C., Wistrom D.W., Swift E.J. (1995): Short-term fluoride release/uptake of glass ionomer restorations. Dental Materials, 11, 96-101. doi: 10.1016/ 0109-5641(95)80041-7

17. Forsten L. (1995): Resin-modified glass ionomer cements: fluoride release and uptake. Acta Odontologica Scandinavica, 53, 222-225. doi: 10.3109/00016359509005976 
18. Grobler S.R., Rossouw R.J., VanWykKotze T.J. (1998): A comparison of fluoride release from various dental materials. Journal of Dentistry, 26, 259-265. doi: 10.1016/ S0300-5712(97)00011-0

19. Hattab F.N., Green R., Pang K., Mok Y. (1989): Effect of fluoride-containing chewing gum on remineralization of caries-like lesions and on fluoride uptake in man. Clinical Preventive Dentistry, 11, 6-11.

20. Strother J.M., Kohn D.H., Dennison J.B., Clarkson B.H. (1998): Fluoride release and re-uptake in direct tooth colored restorative materials. Dental Materials, 14, 129-136. doi: 10.1016/S0109-5641(98)00019-0

21. Wilson A.D., Groffman D.M., Kuhn A.T. (1985): The release of fluoride and other chemical species from a glass ionomer cement. Biomaterials, 6, 431-433. doi: 10.1016/ 0142-9612(85)90107-3

22. Dimkov A., Nicholson W.J. (2016): Releasing of Fluoride Ions From Conventional Glass-Ionomer Cements Incorporated With Antimicrobial Agents. Asian Academic Research Journal of Multidisciplinary, 3(3), 267-287

23. Jedrychowski J.R., Caputo A.A., Kerper S. (1983): Antibacterial and mechanical properties of restorative materials combined with chlorhexidines. Journal of Oral Rehabilitation, 10(5), 373-381. doi: 10.1111/j.1365-2842.1983. tb00133.x

24. Ribeiro J, Ericson D. (1991): In vitro antibacterial effect of chlorhexidine added to glass-ionomer cements. European Journal of Oral Science, 99(6), 533-540. doi: 10.1111/j. 1600-0722.1991.tb01066.x

25. Sanders B.J., Gregory R.L., Moore K., Avery D.R. (2002): Antibacterial and physical properties of resin modified glass-ionomers combined with chlorhexidine. Journal of Oral Rehabilitation, 29, 553-558. doi: 10.1046/j.1365-2842. 2002.00876.x

26. Takahashi Y., Imazato S., Kaneshiro A.V., Ebisu S., Frencken J.E., Tay F.R. (2006): Antibacterial effects and physical properties of glass-ionomer cements containing chlorhexidine for the ART approach. Dental Materials, 22(7), 647-652. doi: 10.1016/j.dental.2005.08.003

27. Palmer G., Jones F.H., Billington R.W., Pearson G.J. (2004): Chlorhexidine release from an experimental glass ionomer cement. Biomaterials, 25, 5423-5431. doi: 10.1016/j.biomaterials.2003.12.051
28. Frenchen J.E., Imazato S., Toi C., Mulder J., Mickenautsch S., Takahashi Y., Ebisu S. (2007): Antibacterial effect of chlorhexidine-containing glass ionomer cement in vivo: a pilot study. Caries Research, 41(2), 102-107. doi: 10. $1159 / 000098042$

29. Block S.S. (1991). Disinfection, Sterilization and Preservation. Fourth Edition. Philadelphia - London: Lea \& Febiger.

30. Chestnutt I.G., MacFarlane T.W., Stephen K.W. (1994): An in vitro investigation of the cariogenic potential of oral streptococci. Archives of Oral Biology, 39(7), 589-593. doi: 10.1016/0003-9969(94)90134-1

31. Ciancio S. (1994): Expanded and future uses of mouthrinses. The Journal of the American Dental Association, 125 Suppl 2, 29S-32S. doi: 10.1016/S0002-8177(94)14005-7

32. DePaola L.G., Minah G.E., Overholser C.D., Meiller TF, Charles C.H., Harper D.S., McAlary M. (1996): Effect of an antiseptic mouthrinse on salivary microbiota. American Journal of Dentistry, 9(3), 93-95.

33. Fine D.H., Furgang D., Lieb R., Korik I., Vincent J.W., Barnett M.L. (1996): Effects of sublethal exposure to an antiseptic mouthrinse on representative plaque bacteria. Journal of Clinical Periodontology, 23(5), 444-451. doi: 10.1111/j.1600-051X.1996.tb00572.x

34. Kubert D., Rubin M., Barnett M.L., Vincent J.W. (1993): Antiseptic mouthrinse - induced microbial cell surface alterations. American Journal of Dentistry, 6(6), 277-279.

35. Netuschil L., Weiger R., Preisler R., Brecx M. (1995): Plaque bacteria counts and vitality during chlorhexidine, Meridol and Listerine mouthrinses. European Journal of Oral Sciences, 103(6), 355-361. doi: 10.1111/j.1600-0722. 1995.tb01857.x

36. Pitten F.A., Kramer A. (2001): Efficacy of cetylpyridinium chloride used as oropharingeal antiseptic. Arzneimittelforschung, 51(7), 588-595. doi: 10.1055/s-0031-1300084

37. Radford J.R., Beighton D., Nugent Z., Jackson R.J. (1997): Effect of use of $0.05 \%$ cetylpyridinium chloride mouthwash on normal oral flora. Journal of Dentistry, 25(1), 35-40. doi: 10.1016/S0300-5712(95)00116-6

38. Botelho M.G. (2003): Inhibitory effects on selected oral bacteria of antibacterial agents incorporated in a glass ionomer cements. Caries Research, 37, 108-114. doi: 10. $1159 / 000069019$ 